\title{
Do semelhante ao mesmo, do diferente ao semelhante: sujeito, ator, agente e protagonismo na linguagem
}

\author{
From the similar to the same, from the \\ different to the similar: subject, actor, agent \\ and protagonism in the language
}

\author{
Dina Maria Martins Ferreira* \\ Universidade Estadual do Ceará \\ Fortaleza, Ceará / Brasil \\ Universidade de Paris V, Sorbonne \\ Paris / França
}

\begin{abstract}
RESUMO: Este artigo visa demonstrar que as prerrogativas das ciências sociais estão imbricadas nos estudos da linguagem no sentido de conceituar sujeito, ator, agente e protagonista. Apesar da tentativa de oferecer conceitos hegemônicos, eles se embaralham diluindo fronteiras de sentido entre si. Uma análise comparativa entre conceitos vinculados a alguns autores, tais como os sociológicos Touraine, Bourdieu e Crozier de um lado e, de outro, os estudiosos da linguagem Pêcheux, Fairclough, Austin, demonstra o entrelaçamento entre linguagem e social. Como exemplo analítico da constituição do sujeito, ator, agente e protagonista, utilizamos a cantora, compositora e poeta brasileira Karina Buhr.
\end{abstract}

PALAVRAS-CHAVE: sujeito; ator; agente; protagonista; linguagem e social.

ABSTRACT: This article aims to demonstrate that the prerogatives of the Social Sciences are imbricated in the Studies of Language in the sense of conceptualizing subject, actor, agent and protagonist. Despite the attempt to offer hegemonic concepts, they shuffle by diluting boundaries of meaning between themselves. A comparative analysis between concepts linked to some authors, such as the sociological ones Touraine, Bourdieu and Crozier on the one hand and, on the other, the language scholars Pêcheux, Fairclough, Austin, demonstrates the interweaving between language and social. As an analytical example of the constitution of the subject, actor, agent and protagonist, we use the Brazilian singer, composer and poet Karina Buhr.

KEYWORDS: subject; actor; agent; protagonist; language; social.

*dinaferreira@terra.com.br 


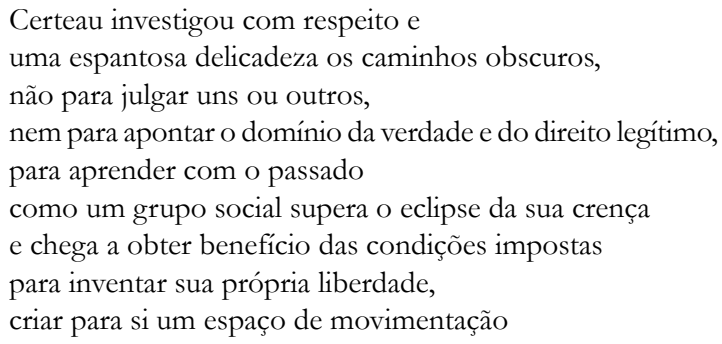

(GIARD, 1995, p. 7).

\section{Considerações Iniciais}

Como estudiosa da linguagem, há anos tenho ouvido/lido/estudado muitas nomenclaturas que dão conta do que chamamos mais genericamente de sujeito da linguagem. Verifiquei que muitas áreas da linguística se arvoram de tomar para si a verdade de quem e o que se constitui na e pela linguagem: no o que, o objeto do discurso, como se objeto e sujeito fossem patamares separados, no quem buscam-se atores sociais, sujeitos e indivíduos que constituem e são constituídos no discurso-linguagem. E nesse quem, a famosa agência, ação que movimenta e transforma o social cujo protagonista também é elencado na linguagem. Trata-se de nomenclaturas que nos colocam em um emaranhado de sentidos, em cujas designações, a cada momento de uso, temos de levantar a área do saber e/ ou autores recrutados até de uma mesma dita área.

É diante desse emaranhado que este artigo se debruça em esforço, para, pelo menos, aventar caminhos (propositadamente no plural), pois, a meu ver, não há uma Verdade em um único caminho, porquanto um único caminho resulta em um tatame em que várias nomenclaturas se engalfinham para exercer o local hegemônico da e na ciência, no caso, estudos da linguagem. Estamos, aqui, pleiteando que temos escolhas que deem conta do que queremos mostrar e apresentar a nossos leitores. E nessa escolha presentifica-se a subjetividade que alguns estudiosos/cientistas ainda negam em prol de uma neutralidade teórica que reina absoluta na hegemonia. Enfim, pelas escolhas que refletem nossa subjetividade, postulamos

Uma nova configuração aos estudos linguísticos, levando em conta não só nossa responsabilidade como linguistas diante da relevância social de nosso trabalho, como também as relações entre linguagem e 
sociedade além de mostrar possibilidades de um estudo científico sobre a lingua(gem) solta das amarras sistêmico-imanentes. O que queremos é reforçar [...] que a prática científica só [pode] ter o direito de existir a partir de sua intervenção na sociedade (MARTINS FERREIRA; ALENCAR, 2013, p. 273).

No primeiro momento vamos percorrer alguns autores que trabalham com as nomenclaturas - indivíduo, sujeito, ator (social), protagonista, agência -, sob a égide dos estudos sociais, para depois aventar as dos estudos da linguagem, elucidando-as, para posteriormente escolher um exemplo analítico como forma de demonstração de nossa(s) escolha(s).

Para reforçar a luta de conceitos e respectivos sentidos no tatame em que nos encontramos, a etimologia de nomenclatura nos auxilia nomen + cla $+(\mathrm{t})$ ura. Se formos ao grego, teremos nomos significando método, lei, regra, mais taxis, que adentra os sentidos de ordem e arranjo. Se nos aproximarmos do latim, teremos nomen+classis $+(t)$ ura, ou melhor, nome de classe, exército, divisão, que por sua vez teve origem em calare, chamar. Se resumíssemos para os dias atuais, diria que nomenclatura é chamar, dar nome a uma lei ou dar nome a uma ordem. Por essas avaliações etimológicas, reconhecemos que somos colocados no tatame de luta pela hegemonia, pois "lei, regra, ordem" são sentidos de comando - obedeçam a determinado conceito-sentido.

Não está se negando o papel da nomenclatura enquanto um próprio (proprius, privado, de si mesmo, propriedade) de determinada área de saber ou de um conceito, até porque não se pode negar que a nomenclatūra facilita, de maneira geral, o conhecimento cientifico. Fora o conhecimento científico, nomenclatura ainda serve para dar propriedade a alguns outros sentidos, tais como: nomeklatura soviética, que referendava uma lista de trabalhos de elevada responsabilidade que deviam ser levados a cabo pelos membros do Partido Comunista. Com o tempo, a palavra passou a ser usada para se referir às pessoas que ocupavam os ditos cargos e que realizavam os trabalhos. Fazer parte da nomenklatura implicava, portanto, ter certa função no aparelho do Estado e diversos benefícios sociais; nomenclatura combinada, que indicava os códigos das mercadorias do sistema aduaneiro (ou alfandegário) comum da União Europeia (UE), adotada em 1987; nomenclatura química, que seria o conjunto de regras que se usam para designar as combinações que existem entre os elementos e os compostos químicos; nomenclatura biológica, que existe como uma autoridade internacional a quem compete estabelecer essas regras; e assim por diante. 
Mas esse rigor classificatório, nos estudos do discurso e da linguagem, muitas vezes, o sentido escorrega, pois ao tentarmos desconstruí-lo não conseguimos deixar de lado o fetiche, ou seja, não há como desconstruir sem precisar voltar ao sentido fixo e sólido que queremos eliminar. Para entender esse argumento utilizo o sentido de inclusão, ou melhor, só posso sentir/praticar a ação da inclusão se retornar à exclusão. Digo, por exemplo, em uma sala de aula: — Todos aqui estão inclusos para desenvolverem suas dúvidas. Ao formular o desejo de inclusão tenho como pressupostos de que há ou houve exclusão. Ou seja, preciso aceitar o próprio da nomenclatura para mostrar que a desambiguação ou os limites fronteiriços de significação nem sempre são possíveis.

Posso entender esse escorregar pelos rastros de significações que nunca se saturam. O sentido está sempre escapulindo, pois é inseparável de um continuum, não consiste numa entidade fechada sobre si mesmo, não compreende uma verdade absoluta, imutável:

Um significante é, de início de jogo, a possibilidade de sua própria repetição, de sua própria imagem ou semelhança. É esta a condição de sua idealidade, o que o faz reconhecer como significante e o faz funcionar como tal, referindo-o a um significado que, pelas mesmas razões, não poderia nunca ser uma "realidade única e singular". Desde que o signo aparece, isto é, desde sempre, não há nenhuma oportunidade de encontrar em algum lugar a pureza da "realidade", da "unicidade", da "singularidade" (DERRIDA, 2011, p. 115, grifo nosso).

E nessa repetição localiza-se a propriedade de iterabilidade da linguagem (DERRIDA, 1991), a qual diz respeito à possibilidade da repetição da marca, do traço de qualquer signo para além do instante em que foi inscrito, bem como para além de quem o inscreveu. E, ao entender que os contextos não se fecham sobre si mesmos e não são determinados rigorosamente de modo absoluto, portanto insaturados, Derrida (1991) argumenta sobre a operação de suplementação, a qual não consiste numa pura adição, numa exterioridade simples de uma presença pura de um significado, mas na ruptura de presença. Assim sendo, diz o filósofo, para que um signo seja legível necessita que seja repetível, repetido - iterável, pois o mesmo tem em si uma força de ruptura com o seu contexto.

E se as nomenclaturas carregam sentidos e sentidos não se saturam, podemos afirmar que os sentidos classificatórios de nomenclaturas são 
da ordem de escolhas que podem adquirir o status hegemônico pela sedimentação de uso que os usuários o qualificam.

\section{Designações: construção de conceitos}

\subsection{Perspectivas sociológicas}

\subsubsection{Sujeito e indivíduo}

Alan Touraine (1992) define o sujeito como sujeito existencial, "um sujeito do mundo, que se sente responsável por si mesmo e pela sociedade" (TOURAINE, 1992, p. 262). Esse sujeito é reflexivo através de sua experiência e do vivido, onde se descobre uma subjetividade pessoal, "que se esforça para se explicar e justificar-se, na obrigação de criar muitas lógicas e de organizar o trabalho de sua experiência" (DUBET, 1994, p. 134). Na perspectiva de Touraine (apud VERONESE; LACERDA, 2011, p. 420), é importante, no âmbito da subjetividade, "compreender $[. .$.$] as mudanças$ atuais na forma de estar e perceber o mundo [que] influenciam na formação de cada indivíduo", ou seja, o sujeito pessoal, combatente, engajado e crítico, inserido nas articulações sociais. O sistema que teria por base uma padronização de desejos perde força para este sujeito pessoal, de vontade, com criatividade, conforme Touraine (apud GUATTARI; ROLNIK, 1993).

Diante desse sujeito criativo e combatente, Touraine faz diferença entre indivíduo e sujeito. $\mathrm{O}$ indivíduo

Não passa [...] de uma tela pela qual se projetam desejos, necessidades, mundos imaginários fabricados pelas novas indústrias da comunicação. Esta imagem de individuo que já não é mais definido por grupos de pertença, que é cada vez mais enfraquecida e que não encontra garantia de sua identidade em si mesmo (TOURAINE, 2006, p. 119).

E o sujeito

É aquele que se revolta contra essa situação, é o devir combatente rebelde, que se volta para si no intuito de buscar a única verdade possível: a sua $[. .$.$] . O sujeito, portanto, configura-se como parte íntima de cada$ ser que possui como movimento a resistência, o confronto, o debate. (VERONESE; LACERDA, 2011, p. 421). 
O que ocorre é que Touraine nega o contexto sociocultural no indivíduo e tira o sujeito da escravidão social. Ambas as posições nos parecem um pouco utópicas. Nem tanto à terra, nem tanto ao mar. Não podemos identificar o indivíduo como uma tábua rasa, em que o social não o toca, como se uma criança, ao ser gerada, nascesse como uma folha em branco. Já é provado que as influências externas atingem o feto. E nem podemos negar ao sujeito a subjetividade reflexiva e pessoal, que acolhe tanto a ação e a agência de uma posição particular influenciando o social, quanto as influências sociais atuando no uso da própria linguagem - vide os estereótipos que nada mais são que sentidos condensados pela estratificação social (BARTHES, 1971).

\subsubsection{Sujeito e ator (agente)}

Para Crozier e Friedberg (1977, p.38), ator não é a mesma coisa que agente, mas "um indivíduo autônomo, capaz de cálculo e de manipulação e que não apenas se adapta, mas inventa, em função das circunstâncias e dos movimentos dos seus parceiros", isto é, um ator é "um construto humano capaz de aproveitar as oportunidades de desenvolver estratégias" (CROZIER; FRIEDBERG, 1977, p. 39), o que nos leva à posição particular de um sujeito, com lugar definido e dinâmico nas relações de dominação e de poder. No entanto, mesmo que ator não seja a mesma coisa que agente (ator está ligado à função e agente à ação), este ator não deixa de ser um sujeito agente de ação concreta. É um ator participante de um coletivo, não mais falado, mas falante e atuante. É importante esclarecer que essa posição particular não é de cunho apenas biográfico, pois sua ação individual está ligada intrinsicamente aos riscos do coletivo social. Sua atuação estratégica no sistema de poder não se dá apenas na relação de dominação, mas também de influência, cooperação e aliança. Para detectar o status de um sujeito ator-agente, a linguagem passa a ser considerada transparente, não apenas de palavras, mas de ação. E neste patamar da argumentação o sujeito ator é um agente performativo na e da linguagem.

\subsubsection{Sujeito e agente (ator)}

Dubar (2004), agente, ator e sujeito seriam modalidades, senão formas identitárias, que compõem a identidade social dos indivíduos. Ou melhor, "traduzem denominações diferentes que serão consideradas como sintomas das 
distintas maneiras do fazer sociológico" (científico) (DUBAR, 2004, p. 57, grifo do autor). Esse autor faz uma discussão de tais nomeações, optando por elucidar o que o sociólogo científico chama de sujeitos sociais: "Os sujeitos sociais se tornam agentes, isto é, indivíduos considerados na prática e imersos na ação, agindo por necessidade” (BOURDIEU, 1994, p. 67). Esse sociólogo científico rompe com suas crenças, não imputando sua própria visão sobre tais sujeitos, mas objetivando, ou seja, imputando a esses sujeitos sociais os esquemas de habitus (BOURDIEU, 1984), o que os transforma em "produtos do mundo social" (BOURDIEU, 1994, p. 166) e não em indivíduos isolados. Nessa perspectiva, não se nega a linguagem popular dos indivíduos como performativa, apenas reforça que os sujeitos sociais estão no sistema, ou melhor, os sentidos de sujeitos sociais advêm do sistema com seus estereótipos: os sentidos não pertencem aos indivíduos mas ao sistema. Isso não quer dizer que esse sujeito social seja fixo, pois, como diz Bourdieu (1984), habitus é uma estrutura estruturante, um sistema com movimento, passível de modificações e mudanças, porquanto no estruturante da estrutura habita a possibilidade de mudança e de movimento das regras e normas sociais.

O que se percebe no pensamento bourdieusiano é que está se falando de sujeito e agente no patamar do coletivo, um sujeito social cativo do sistema. A ação da e na linguagem comum seria uma illusio, um in-ludere, brincar dentro, ou seja, uma ação constitutiva do agente sem consciência, na medida em que esta agência é ação inoperante de sentidos, porquanto são sujeitos falados e não que falam. É apenas na linguagem operacional, resultado de observação e inscrição em fatos sociais, que se estabelece o verdadeiro agente, pois se inscreve nas relações sociais "como instrumento de dominação e poder" (BOURDIEU, 1994, p.67).

\subsubsection{Sujeito ator-agente-protagonista}

Como se pode perceber, os sociólogos Crozier e Friedberg, Bourdieu e Touraine, ora seamalgamam, ora se diferenciam, criando fronteiras fluidas entre as designações ator, agente e agora protagonista, porquanto Touraine age com vistas à transformação de uma ordem, o que em Bourdieu permanece transcendente ao "agente", e o qual o ator de Crozier apenas negocia.

Bourdieu (1983 apud SOUZA, [20--?]) ao atribuir maior ênfase na reprodução das relações sociais, como já foi mencionado, defende a 
existência de um habitus incorporado pelos agentes como esquemas de apreensão de uma estrutura objetiva, habitus este que é construído no interior de um campo social onde os agentes ocupam determinadas posições segundo a distribuição dos diferentes tipos de capital (econômico e o cultural), e que são reveladoras de relações de dominação. E, como afirma Ortiz (1983, p.26), na teoria sociológica desenvolvida por Bourdieu, a questão da mudança não assume importância fundamental, mas trata-se de acentuar, sobretudo, as relações de poder presentes no mundo social, assim como a reprodução de uma estrutura objetivada interiorizada pelos agentes.

Diferentemente de Bourdieu, Touraine (1998) trata o ator social enquanto um agente de mudança, porquanto o ator social é alguém que, "engajado em relações concretas, profissionais, econômicas, mas também igualmente ligado à nacionalidade ou gênero, procura aumentar a sua autonomia, controlar o tempo e as suas condições de trabalho ou de existência" (TOURAINE, 1998, p. 37).

Para Pierre Bourdieu o ator é um "agente"; [...]: em Michel Crozier ele se transforma em "estratego" de um jogo institucional, por fim, o ator de Alain Touraine compartilha com o ator de Bourdieu uma situação de conflito que emerge de relações de dominação, e com Crozier um estatuto de ator coletivo, o qual reconhece em si mesmo interesses e projetos próprios (SOUZA, [20--?]).

Mas onde está o ator protagonista do ponto de vista sociológico? Quem nos responde, neste momento, é Leonardo Boff (2015), já que, de maneira geral, os sociólogos não abordam o ator-agente protagonista, pois, excetuando Touraine, a visão é sempre coletivo-social. Boff se utiliza de vários sentidos de "povo", mas ficamos com sua perspectiva históricosociológica, em que o "povo' é cooptado como ator secundário de um projeto formulado pelas elites e para as elites” (BOFF, 2015, p. 2). O povo seria $\mathrm{o}$ ator secundário, na medida em que está subalterno à elite. Mas o que entendemos como protagonista está em sua avaliação de que "há rachaduras no processo de hegemonia ou dominação de classe: lentamente, da massa, surgem lideranças carismáticas que organizam movimentos sociais com visão própria" (Boff, 2015, grifo nosso) - de ator secundário surge um ator protagonista - um líder, como "cidadão ativo e relativamente autônomo". A própria etimologia de protagonismo nos alia ao pensamento de Boff (2015), do latim protos, principal, primeiro, e agonistes, lutador, competidor. Como lutador e agente de mudança (TOURAINE, 1998), talvez o protagonista 
seja um agente, um indivíduo que lidera a mudança, não deixando nem de ser um ator social, nem um agente, que emerge do coletivo, que representa um coletivo e que tem uma posição particular, mas que é construída no sistema social.

\subsection{Perspectivas discursivo-linguageiras}

Neste primeiro momento deste item, vale a informação de que fazer diferença entre linguagem e discurso não faz sentido à nossa proposta, por estarem imbricados. O que nos interessa é abordar linguagem/discurso diretamente ligados ao social, e quem mais privilegia esse aspecto são as noções de discurso como prática social e sua natureza performativa, ou seja, de que falar é agir: "O discurso é um modo de agir uma forma pela qual as pessoas agem em relação às outras pessoas" (FAIRCLOUGH, 2001, p.63). Segundo Fairclough (2001, p.64) “existe uma relação dialética entre o discurso e a estrutura social, havendo portanto uma relação entre prática social e estrutura social, em que a segunda é tanto uma condição para a primeira quanto um efeito dela", ou seja, o discurso é a base da estrutura social, pois ele não apenas representa suas convenções, mas também as constitui e molda, fazendo com que o mundo e as relações sociais adquiram significados.

E, abordando a linguagem em sua natureza performativa, damos ao sujeito a responsabilidade de seus atos de fala, que com sua força ilocucionária projeta efeitos de sentido (força perlocucional) (AUSTIN, 1975), no processo interativo e comunicativo que nada mais é que uma relação social que se estabelece entre sujeitos, em um espaço e tempo cultural e político.

Tendo por base essas perspectivas sobre a linguagem, podemos aventar sobre os significados de sujeito, ator social, agente e protagonista.

\subsubsection{Sujeito discursivo: assujeitamento, práxis social e performatividade}

Se fôssemos percorrer todas as prerrogativas teóricas do sentido de sujeito discursivo/da linguagem, atravessaríamos um vasto percurso teórico, por isso optamos por nos deter no sujeito discursivo de três autores: Pêcheux (Análise do discurso francesa), Fairclough (Análise crítica do discurso) e Austin (Teoria dos atos de fala), em que cada um formula, a sua maneira, a relação linguagem/social. 
Sob a perspectiva francesa da análise do discurso (PÊCHEUX, 1988), o sujeito discursivo

Tem sua materialidade linguística, e, portanto, fruto de um entremeio entre metafóricos, metonímicos, paráfrase e polissemia, ele significa e é significado em determinadas condições pelo viés do interdiscurso, que sustenta seu dizer. Ele não é quantificável ou normatizável, mas é inscrito na/pela memória discursiva, que, por sua vez, está inscrita nas formações discursivas, que são inscritas nas formações sociais, e que se constituem nas injunções ideológicas (PATTI, 2012, p. 19, grifo nosso).

Para Pêcheux (1988, p. 163) “o sujeito se constitui pelo 'esquecimento", um esquecimento em que o sujeito-falante não pode se encontrar na formação discursiva em si, e que dá a ilusão de que o falante pode escolher as palavras, já que "uma palavra, uma expressão ou uma proposição não tem um sentido que lhe é 'próprio' vinculado a sua literalidade [mas sim] mudam de sentido segundo as posições sustentadas por aqueles que as empregam" (PÊCHEUX, 1988, p. 160-161).

O que se percebe é que esse sujeito discursivo não tem voz, ele é constituído só pela materialidade linguística, pelo esquecimento e pela memória discursiva - nem é falado nem é falante, e como tal não pode ser ator nem agente, pois não age e, por consequência, não protagoniza (lutar e reivindicar). Ele é assujeitado à linguagem, mesmo que o discurso tenha respaldo nas estruturas sociais e na história que o envolvem.

Mesmo que a "ideologia seja um fator para a constituição do sujeito e dos sentidos" (ORLANDI, 1999, p.46), e que se postule que é a linguagem que faz sentido porque está inscrita na história, mediando homem e realidade social (SANTOS, 2009), e que apregoe que é o discurso que transforma o "homem e a realidade em que ele vive" (ORLANDI, 1999, p.15), parecenos que este sujeito discursivo não é um ator social, apenas o discurso em si parte de um produtor e se dirige a um receptor que está de fora. Afinal "ao sofrer a determinação da ideologia, por via da interpelação, o sujeito se configura como assujeitado" (FERREIRA, 2010, s/p.) Poderíamos, com os cuidados teóricos necessários, dizer que a linguagem é mais importante que o homo, quando, a meu ver, poderia ousar dizer que homem é linguagem.

Neste momento, vamos aliar Fairclough (2001) a Austin (1975), não para anular as diferenças das perspectivas teóricas de cada autor, mas justamente para amalgamar a intrínseca relação entre linguagem e social que tais autores estabelecem. 
Wodak (2003, p. 31), a respeito da teoria faircloughiana nos diz que a "A ACD se interessa pelos modos em que se utilizam as formas linguísticas em diversas expressões e manipulações do poder". Já o postulado de Pedrosa (2005, s/p) mostra que

A relação entre discurso e estrutura social tem natureza dialética, resultando do contraponto entre a determinação do discurso e sua construção social. No primeiro caso, o discurso é reflexo de uma realidade mais profunda, no segundo, ele é representado, de forma idealizada, como fonte social. A constituição discursiva de uma sociedade decorre de uma prática social que está, seguramente, arraigada em estruturas sociais concretas (materiais), e, necessariamente, é orientada para elas, não de um jogo livre de ideias na mente dos indivíduos.

E o próprio Fairclough (2001) apresenta um sujeito não mais assujeitado, mas que pode se contrapor à dominação, ou melhor, se de um lado os sujeitos sociais são capazes de provocar mudanças sociais, de outro, são moldados pelas práticas discursivas. Já saímos, então, de um sujeito do esquecimento de Pêcheux, acionado pela memória discursiva. Este sujeito faircloughiano já tem possibilidades de ser um ator que age e reage, logo, agente. Nessa perspectiva, mesmo sendo o discurso um modo de ação - como as pessoas agem sobre o mundo e sobre as outras -, é também modo de representação. E, na medida em que o discurso é uma prática de representação e de significação de mundo, moldado pelas estruturas sociais, a agência ainda não é autônoma de um combatente criativo.

Mas é com Austin (1975) que temos a linguagem com sua natureza performativa, de que falar é agir, dizer é agir, mesmo que o ato de fala seja excessivamente centrado no falante individual. Logo bandearíamos para um sujeito atuante (ator e agente), não coletivo, mas individual, com todas as prerrogativas de ação e responsabilidade: "O significado do signo (palavra) ou da construção da sentença, mas da situação comunicativa, do contrato estabelecido entre os participantes da interação entre esses participantes" (LEITE, 2009, p. 196). O ato de fala não foge da questão das relações de assimetria/poder, pois determinados atos performativos são proferidos por sujeitos autorizados, por exemplo, só pratica o ato de batizar o sujeito autorizado socioculturalmente.

Se resumíssemos as três modalidades de sujeito discursivo escolhidos para nossa proposta, o sujeito assujeitado seria um locutor incapaz da criação de um discurso novo, reproduzindo apenas discursos anteriores 
consolidados, logo não poderia ser um agente; o sujeito discursivo, ligado à práxis social, pode remodelar e protestar, e mesmo que esteja vinculado às representações das estruturas sociais não deixa de ser um sujeito em práxis social; e o sujeito da ação, de uso da linguagem enquanto performativa, é capaz de agenciar seu próprio discurso, mesmo quando lhe é exigido a autoridade sociocultural de caráter institucional.

\subsection{Do semelhante ao mesmo e do diferente ao semelhante}

Fazendo, agora, a correlação entre sujeitos de perspectivas sociológicas com os sujeitos discursivo-linguageiros, o próprio título deste item os explicaria, pois há semelhanças que chegam ao mesmo conceito e diferenças que chegam a conceitos semelhantes, demonstrando a intrínseca relação entre linguagem e social.

O sujeito touraineano de posição particular, engajado, pode estar no sujeito austiniano, por estar centrado no particular, em uma posição de ação e responsabilidade diante de sua agência - é o eu agindo pela linguagem. E, como agente, é um ator cuja ação pode ter efeitos sociais. Este mesmo sujeito combatente pode se tornar um protagonista, tanto pela sua posição criativa quanto pela sua performatividade inserida na linguagem.

O sujeito social bourdieusiano, não mais em posição particular, pode se referir ao sujeito faircloughiano na medida em que ambos estão inseridos em práticas sociais, mesmo que clivados pela estrutura social.

Para adentrar na questão sobre agência/protagonismo na linguagem (AHEARN, 2001), ficamos sociologicamente com o sujeito touraineano e filosófico-linguisticamente com o austiniano, mesmo que cada um deles tenha suas limitações relacionais entre si, pois, em ambos, podemos tocar em um sujeito criativo, capaz de combater e reivindicar.

A grande questão está em delimitar o que é agência do sujeito na linguagem (AHEARN, 2001), o que distingue um ator de um agente e como $\mathrm{o}$ agente pode se tornar protagonista.

Ator e agente podem ser considerados aspectos diferentes de uma mesma pessoal, até porque vários tipos de agência são frequentemente inseparáveis na prática (AHEARN, 2001). Podemos considerar dois tipos de agência: uma como desejo livre e outra como ação de resistência. $\mathrm{Na}$ questão de agência como um desejo, é preciso perguntar se neste tipo de agência livre não entra em questão a intenção (DAVIDSON, 1980), a presença do eu (SEGAL, 1991), o ponto de vista racional e um controle 
intencional de comando (ROVANE, 1998). No entanto, até então, o levantamento do conceito de sujeito ator-agente nos mostrou um sujeito particular combatente. E, por tal característica, aventar a ideia de que haja agência de maneira inconsciente é refutar a existência de um sujeito criativo que, para tal, precisa de uma agência mental e um consequente domínio de suas intenções. Sem tais características não haveria possibilidade de ação no quesito mudança social.

Tendemos por optar pelo lado de uma agência na linguagem pela agência-resistência, pois é nela que a linguagem demonstra as relações de poder que são combatidas por tais sujeitos-agente, que adquirem determinada posição de ator, senão de protagonista. Um exemplo seria a agência feminista contra a dominação do patriarcado, em luta e com criatividade, para desconstruir os estereótipos que continuam a habitar a estrutura social. Este agente contra a opressão é um ator que se arvora de agência, cujo contexto lhe permite agir ou furar o cerco. O agente-ator está no tatame das relações de poder, mesmo que em alguns momentos não possa lutar contra, não deixa de ter intenção de mudança. Foucault (1978, p. 93-95) justamente nos mostra o tatame onde o sujeito agente atua:

Poder está em toda parte; não porque ele abraça tudo, mas porque vem de toda parte. E "O poder", na medida em que é permanente, repetitivo, e auto-reprodutivo, é simplesmente o efeito global que emerge de todas essas mobilidades, a concatenação que repousa sobre cada uma delas e busca, por sua vez, deter seu movimento [...] não há poder que seja exercido sem uma série de intenções e objetivos, mas isso não significa que resulte da escolha ou decisão de um indivíduo.

Quando se fala em agência estamos nos referindo à capacidade humana de agir, não esquecendo de que tais ações são dialeticamente relacionadas à estrutura social, de uma maneira mutuamente constitutiva (AHEARN, 2000). Nesta vertente de agência como resistência, há também atos agentivos que envolvem cumplicidade, acomodação e reafirmação do status quo. Alessandro Duranti (1994), em seus estudos sobre a agência em Samoa, nos chama a atenção para a agência humana na linguagem, demonstrando como a agência-resistência é modelada em formas linguísticas pelo usuário falante, ou seja, faz a diferença entre verbos ergativos, transitivos e intransitivos, entre outras marcas linguísticas, para demonstrar as ações humanas com seus formatos linguísticos em relação às estruturas sociais engendradas na linguagem. 
É pela agência contra a opressão, combatente, que nos surge o protagonista. Giddens (2005, p. 47, grifo nosso), já abre portas para aliar a ação (agente) ao protagonismo: "Temos de moldar nossas vidas de uma maneira mais ativa do que o fizeram gerações anteriores, e precisamos aceitar mais ativamente responsabilidades pelas consequências do que fazemos e dos hábitos de estilo de vida que adotamos". E, como diz Alves (2012, p. 3), em concordância com Giddens (2005), "os intelectuais - pessoas e organizações - constituem-se nos agentes da consolidação do novo projeto de sociabilidade e a organicidade estabelecida entre organizações e pessoas deve ser considerada fundamental nesse movimento". Agência teria o foco de "ajustar os cidadãos a abrir seu caminho através das mais importantes revoluções de nosso tempo: globalização, transformações na vida pessoal e nosso relacionamento com a natureza" (GIDDENS, 2005, p. 74).

Nas agências contra a opressão e para as mudanças sociais, tanto o sujeito particular quanto o sujeito social se encontram emparelhados, da mesma forma que um líder carismático (BOFF, 2015) e uma pessoa comum criativa e combatente (CERTEAU, 1995; TOURAINE, 1998), porquanto suas agências teriam focos estratégicos (CROZIER; FRIEDBERG, 1977; CERTEAU, 1995) para alcançar um fim. Ao buscar um fim, essa agência se transforma em protagonismo, pois corresponderia a um tipo de linguagem emancipatória e autônoma que visa a uma reformulação social. Não estaria aí, também, o conceito da performatividade da linguagem? Conforme Austin (1975), o sujeito agente, agora sujeito protagonista, age em determinadas circunstâncias - ação que gera (força ilocucionária) e que gera algo consequência/efeito desse gerar (força perlocucional). O protagonismo assim cumpre o seu papel. Em outra medida teórica (FAIRCLOUGH, 2001), aceitando que a prática social possibilita ações, estas estabelecem uma relação transformacional entre estrutura social e agência, constituindo o social da linguagem.

Se em toda ação-agente o protagonista age com um propósito, neste propósito, ele "mergulha nos acontecimentos a fim de potencializá-los criativamente, 'inventando formas de viver na diferença, sem impor um consenso, um controle regulador"' (GALLO, 2007, p. 35). E na criatividade se esconde um emaranhado de astúcias, que Certeau (1994), chama de táticas e estratégias. A tática depende do tempo, vigiando o momento das possibilidades de ganho, para transgredir as regras instituídas, ou melhor, transformar os acontecimentos em ocasiões. Para Josgrilberg, (2005, 
p. 23), as "táticas organizam um novo espaço, o que é o lugar praticado". A estratégia seria "o cálculo das relações de forças que se tornam possíveis a partir do momento em que um sujeito de querer e poder é isolável de um ambiente" (CERTEAU, 1994, p. 46), porquanto as estratégias escondem, sob o cálculo de objetivos, a sua relação com o poder que as sustenta, guardada pela instituição: uma linguagem, uma vez falada, implica pontos de referência, fontes, uma história, ou seja, uma articulação de autoridade" (CERTEAU, 1995, p. 34).

Assim, tática seria um cálculo que não pode contar com um próprio, pois só tem por lugar o do outro; e a estratégia, um cálculo de relações de força, em que postula um lugar capaz de ser circunscrito como um próprio.

Resumindo o já dito, o sujeito agente-protagonista age - no social e na linguagem, performatizando, demonstrando uma força de criatividade (de mudança na estrutura social e, na linguagem, a força ilocucionária), que busca um propósito articulado por táticas e/ou estratégias. Enfim, teríamos uma ação que se torna fato, resultado da ação que transforma, e que transborda na linguagem pelos efeitos gerados pela força da ação, efeito perlocucional, seja este agente-protagonista (ator também, pois assume uma função) um sujeito individual (TOURAINE, 1998; AUSTIN, 1975) ou social, líder (BOFF, 2015), ou pessoa comum (CERTEAU, 1994, 1995; CERTEAU; GIARD; MAYOL, 1997).

\section{2 (Não)protagonismo no discurso de gênero feminino}

Os exemplos a seguir não constituem uma análise linguístico-social em detalhes, mas estão mais para uma ilustração da aplicação de conceitos aventados anteriormente.

Antes de adentrarmos no protagonismo da linguagem, preferimos chamar a atenção para o sujeito assujeitado (não-protagonista), que em algumas circunstâncias pode ser aliado, em certa medida, ao sujeito bourdieusiano no que tange à escravidão do sujeito ao social, ao sujeito que é falado e não fala, ao habitus que o engole, minando possibilidades de ação. Na Folha de S.Paulo de 24 de dezembro de 2016, p. B7, em reportagem de Julio Abramczyk, a manchete no meio da folha diz: "É preciso agir para incluir mais mulheres na ciência" e, como submanchete: "Diretor do Instituto Weizmann de Ciências fala sobre sua política para contratar pesquisadoras e torná-las chefes". Nessa reportagem, o que temos são dois sujeitos masculinos que se constroem no discurso, mas que atuam, dando 
força às suas vozes: o jornalista pela sua assinatura e perguntas da entrevista e o diretor-médico do instituto, pela sua foto no meio da reportagem e por suas respostas na entrevista. Mas também se verifica o sujeito feminino assujeitado na submanchete - "é preciso [...] incluir mais mulheres na ciência" - , tanto por ser veiculado pelas vozes masculinas quanto pelo fato de serem faladas e não falarem. Esse sujeito feminino, constituído dentro do discurso, sem dúvida, tem seu vínculo com o social, mas um social representado pelo masculino que dá chance ao feminino que não tem o seu próprio; é o poder falocrático que fala pelo feminino e que tem o poder de dar chance ao feminino de ocupar um lugar social. Este sujeito feminino assujeitado é constituído pela e na linguagem que reflete, pelo menos, uma sociedade de relação de poder calcada no poder masculino.

E a nossa protagonista-agente-atora é um sujeito particular - a artista (compositora, poeta e cantora) brasileira Karina Buhr - que, como protagonista de movimento feminista, fez de seu terceiro disco, Selvática, lançado no ano de 2015, um manifesto contra o falocrático e a favor de sermulher. Como protagonista, sua ação agentiva teve consequências, como atora na função de artista e cantora, é agente criativa dentro deste manifesto, pois construiu seu lugar próprio ao alcançar respostas por este disco: boa parte da crítica musical brasileira denominou o disco de feminista. Seu agenciamento se inicia pelo próprio título do disco, Selvática, sobre o qual justifica sua escolha:

Este nome eu tirei do Gênesis, da Bíblia, que fala de uns animais selváticos, que são os bichos escrotos: ratos, serpentes, escorpiões. E depois, quando entra a mulher em cena, comecei a viajar que ela também seria selvática, por tudo que rolou na história até hoje e como elas são representadas também nestes textos todos: sempre que tem mulher é relacionado à traição, à fraqueza.

Além do propósito da escolha do título do disco Selvática, a escolha de Buhr (com um propósito) se expande por outros agenciamentos, tais como discurso bíblico, gênero e música, demonstrando o caráter performático e iterável da linguagem, de onde se constitui uma atora guerreira. Burh é um sujeito particular feminista, com a intenção de valorizar o ser-mulher, cuja potência de sentido a transforma em agente de um movimento, em que o papel desempenhado - artista, cantora e compositora - a torna atora-agente de um protagonismo. Seu protagonismo, o seu próprio, provoca efeitos da 
força advindos de sua agência, pois ao atingir as redes sociais intensifica a divulgação do disco.

Karina Buhr divulgou a capa de Selvática, seguida de uma das músicas que compõe o disco - a faixa "Eu sou um monstro". De imediato, ouve-se um discurso feminista na letra dessa música, de autoria da própria cantora, quando nos diz "Hoje eu não quero falar de beleza / Ouvir você me chamar de princesa / Eu sou um monstro". Entendemos a divulgação da capa do disco e da música como uma ação feminista, cuja agência atualizada na performatividade da linguagem a transforma em protagonista.

Além disso, os efeitos perlocucionais se intensificam pela própria imagem que constitui a capa do disco, censurada por redes sociais: uma fotografia da cantora posando com os seios expostos e com as mãos segurando um punhal:

Capa do disco Selvática, de Karina Buhr

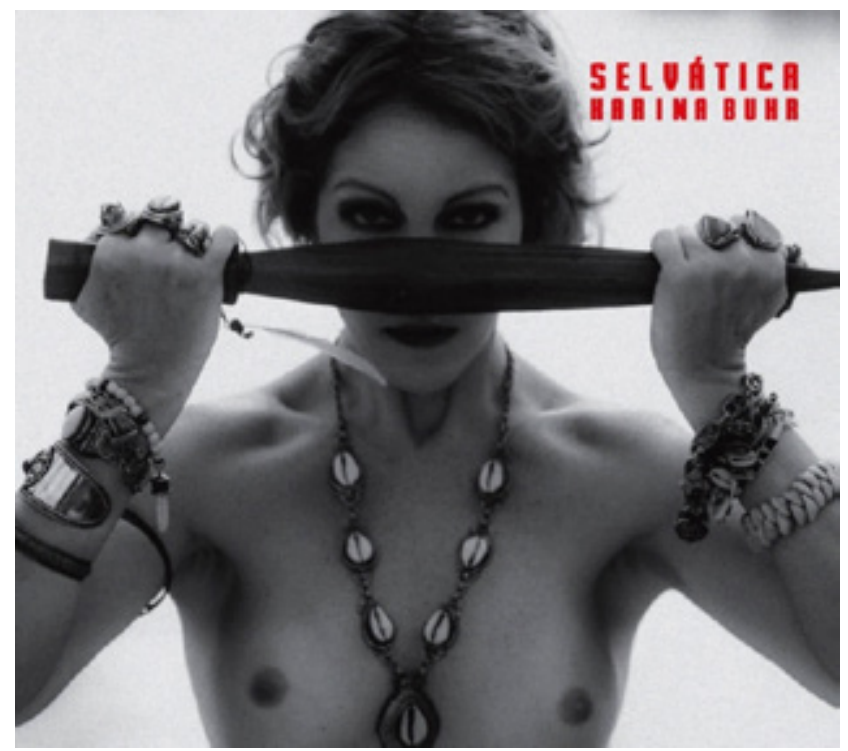

Os efeitos de seu propósito-ação continuaram diante da censura do Facebook, e geraram: uma série de postagens em apoio à cantora, de textos de vários usuários que postaram imagens de outros discos que continham imagens de seios expostos; defesa a Buhr pelo Ministério da Cultura (MinC), do Governo Federal, por meio da página da Secretaria da Cidadania e da Diversidade Cultural (SCDC). E o caminho dos efeitos não terminou, 
pois o Ministério também sofreu censura, ao compartilhar na rede a capa de Selvática, quando se manifestou em favor da artista: a página da SCDC ficou fora do ar por um tempo e seus administradores tiveram seus perfis bloqueados. Além disso, a jornalista Aline Feitosa e o fotógrafo Beto Figueiroa, na cidade do Recife, lançaram uma ação-arte-manifesto intitulada Selváticas, em que catorze mulheres, entre elas Karina, protagonizaram fotografias com os seios à mostra, cujo manifesto se delineou a partir do direito à liberdade de expressão na referida rede social, contra a sexualização (ou disciplinarização) do corpo feminino. Aline Feitosa abre mais afluentes aos efeitos, pois também teve seu perfil na rede bloqueado ao postar uma foto em que se encontra sem blusa, ao qual contra-argumentou - "Não estamos nuas. Estamos sem blusa".

Parece que, com tantos efeitos, não se pode questionar a agência protagonista de Karina Buhr. Em seu protagonismo usou a sua fala, articulou sua agência-protagonista pela estratégia, agiu pelo seu próprio (Karina), postulando o seu lugar, um lugar em que foi capaz de falar por si própria, constituído pelo seu eu.

\section{Considerações finais}

Este estudo se iniciou por duas paralelas, uma constituída por conceitos na área de ciências sociais e outra pelos estudos da linguagem. À medida que essas paralelas vão caminhando em nossa argumentação, vão ondulando, e nestas ondulações as linhas vão se tocando ora em harmonia, ora em diferença, demonstrando que não há como separar linguagem do social. Ambas as linhas traçam o sujeito individual, chega a sujeito social, do sujeito social chega-se ao ator - o sujeito que assume uma função social a qual deve e quer desempenhá-la - e por tal função age, cuja agência permite que adquira a propriedade de agente. Ao assinalar que sua agência tem um propósito, se torna protagonista de uma ação social que visa à transformação e à mudança.

Nenhum dos sociólogos adotados detém a verdade do mesmo modo que os estudiosos da linguagem. O que ocorre é que eles se amalgamam de acordo com nossa escolha argumentativa. Como diz Santos (2010), estamos na ecologia do saber em que o paradigma emergente nos envolve como cientistas: 
conhecimento não dualista, um conhecimento que se funda na superação das distinções, enfim, um colapso das distinções "até então consideradas insubstituíveis;

fragmentação pós-moderna não é disciplinar e sim temática. Os temas são galerias por onde os conhecimentos progridem ao encontro uns dos outros;

o objeto é continuação do sujeito [...] por outros meios. Por isso, todo o ato criativo protagonizado por cada cientista [...] [o cientista] tem de se conhecimento científico é autoconhecimento. A ciência não descobre, cria, e o conhecer intimamente antes que conheça o que com ele se conhece do real;

o conhecimento do senso comum, o conhecimento vulgar e prático com que no quotidiano orientamos as nossas ações e damos sentidos à nossa vida, porquanto subjaz-lhe uma visão do mundo assente na ação e no princípio de criatividade e da responsabilidade individuais (SANTOS, 2003, p. 64-89).

Se o "pensamento abissal é a impossibilidade da co-presença dos dois lados da linha” (SANTOS, 2010, p. 33), o pensamento de fronteira que não visa à exclusão de uma das linhas, pois pleiteia o diálogo de saberes. Já "o pensamento pós-abissal parte da ideia de que a diversidade do mundo é inesgotável e continua desprovida de uma epistemologia adequada”. Em outras palavras, "a diversidade epistemológica do mundo continua por construir" (SANTOS 2010, p. 51), acreditando que "existir é ser chamado à existência em nome de uma alteridade" (BHABHA 1998, p.110).

Enfim, nenhuma das linhas paralelas, até porque são paralelas, nos faz reproduzir uma geopolítica do conhecimento que classifica e hierarquiza saberes conferindo a predominância de um saber que tem o autopoder de se considerar universal (PORTO-GONÇALVES, 2005). Pleiteamos neste artigo a ecologia do saber entre áreas, entre teóricos, entre conceitos, a fim de demonstrar possibilidades de criações outras para além dos cânones.

\section{Referências}

ABRAMCZYK, J. É preciso agir para incluir mais mulheres na ciência. Jornal Folha de S. Paulo, 24 dez. 2016. p. B7.

AHEARN, L. Agency. Journal of Linguistic Anthropology, Hoboken, v. 9. n. 1-2, p. 12-15, 2000. https://doi.org/10.1525/jlin.1999.9.1-2.12. 
AHEARN, L. Language and Agency. Annual Review of Anthropology, Palo Alto, v. 30, p. 109-137, 2001. https://doi.org/10.1146/annurev.anthro.30.1.109.

ALVES, M. C. M. Protagonismo docente: a configuração de um perfil docente à lógica do capital. In: ANPED SUL, IX., 2012, Caxias do Sul. Anais... Caxias do Sul: Universidade da Caxias do Sul , 2012. Disponível em: < http://bit.ly/2nQ1mB7>. Acesso em: 20 dez. 2016.

AUSTIN, J. L. How to do Things with Words. 2nd ed. Massachusetts: Harvard University Press, 1975. https://doi.org/10.1093/acprof:oso/9780198245537.001.0001.

BHABHA, H. O local da cultura. Tradução Myriam Ávila, Eliana L. de Lima Reis e Gláucia R. Gonçalves. Belo Horizonte: UFMG, 1998.

BARTHES, R. Elementos de Semiologia. Tradução Izidoro Blikstein, São Paulo: Cultrix, 1971.120p.

BOFF, L. Em busca de um conceito de povo: de ator secundário a protagonista.

O Tempo, Belo Horizonte, p. 1-5, 6 fev. 2014. Disponível em: < http://bit. ly/2nkxxEZ>. Acesso em: 23 dez. 2016.

BOURDIEU, P. Méditations pascaliennes. Paris: Seuil, 1994.

BOURDIEU, P. Questões de sociologia. Tradução Jeni Vaitsman. Rio de Janeiro: Marco Zero, 1983.

BOURDIEU, P. Homo Academicus. Paris: Les Éditions de Minuit, 1984.

CERTEAU, M.; GIARD, L.; MAYOL, P. (Org.). A invenção do cotidiano 2: morar e cozinhar. Tradução Carlos Nelson Coutinho e Leandro Konder. Petrópolis: Vozes, 1997.

CERTEAU, M. A cultura no plural. Tradução Enid Abreu Dobránszky. Campinas: Papirus, 1995. (Coleção Travessia do Século).

CERTEAU, M. A invenção do cotidiano 1: as artes de fazer. Tradução Ephraim Ferreira Alves. Petrópolis: Vozes, 1994.

CROZIER, M.; FRIEDBERG, E. L'acteur et le système. Paris: Seuil, 1977.

DAVIDSON, D. Agency. In: DAVIDSON, D. (Ed.). Essays on Actions and Events. Gloucestershire: Clarendon Press, 1980. p. 43-61.

DERRIDA, J. Gramatologia. Tradução Miriam Chnaiderman e Renato Janine Ribeiro. 2. ed.. São Paulo: Perspectiva, 2011.

DERRIDA, J. Assinatura, acontecimento, contexto. In: DERRIDA, J. Margens da filosofia. Tradução Joaquim Torres Costa e António M. Magalhães. São Paulo: Papirus, 1991. p. 349-373. 
DUBAR, C. Agente, ator, sujeito, autor: do semelhante ao mesmo. Paris, p. 56-69, primavera 2004. Disponível em: < http://bit.ly/2nAIqUI>. Acesso em: 10 nov. 2016.

DUBET, F. Sociologie de l'expérience. Paris: Seuil, 1994.

DURANTI, A. From Grammar to Politics: Linguistic Anthropology in a Western Samoa Village. Berkley: University of California Press, 1994.

FAIRCLOUGH, N. Discurso e mudança social. Tradução Isabel Magalhães. Brasília: UnB, 2001.

FERREIRA, M. C. L. Análise do Discurso e suas Interfaces o lugar do sujeito na trama do discurso. Organon, Porto Alegre, v. 24, n. 48, 2010. Disponível em: <http://bit.ly/2nAAUJs >. Acesso em: 10 dez. 2016.

FOUCAULT, M. The History of Sexuality: volume 1: an Introduction. New York: antheon, 1978.

FOUCAULT, M. The History of Sexuality: volume 2: the Use of Pleasure. New York: Pantheon, 1978.

GALLO, S. Acontecimento e resistência: educação menor no cotidiano da escola. In: CAMARGO, A. M. F; MARIGUELA, M. (Org.). Cotidiano escolar: emergência e invenção. Piracicaba: Jacintha, 2007, p.21-39.

GIARD, L. A invenção do possível. In: CERTEAU M. C. A cultura no plural. Tradução Enid Abreu Dobránszky. Campinas: Papirus, 1995. p. 7-16.

GIDDENS, A. A terceira via: reflexões sobre o impasse político atual e o futuro da social-democracia. 5. ed. Tradução Maria Luiza X. de A. Borges. Rio de Janeiro: Record, 2005. (Coleção Pensando na Crise).

GUATTARI, F.; ROLNIK, S. Micropolitica: cartografias do desejo. Tradução Laymert Garcia dos Santos, Jose Miguel Wisnik e Modesto Carone. Petrópolis: Vozes, 1993.

JOSGRILBERG, F. B. Cotidiano e invenção: os espaços de Michel de Certeau. São Paulo: Escrituras, , 2005. (Coleção Ensaios Transversais).

LEITE, L. P. V. Considerações sobre o sujeito na linguagem: da língua ao discurso. Vernaculum: Flor do Lácio, Petrópolis, v. 1, n. 1, p. 192-202, 2009. Disponível em: <http://bit.ly/2nEKnkO>. Acesso em: 15 dez. 2016.

MARTINS FERREIRA, D. M.; ALENCAR, C. N. Por uma "nova pragmática emancipatória". Trabalhos em Linguística Aplicada, Campinas, v. 52, n. 2, p. 271-285, jul./dez. 2013. https://doi.org/10.1590/S0103-18132013000200006.

ORLANDI, E. P. Análise de discurso: princípios e procedimentos. Campinas: Pontes, 1999. 100p. 
ORTIZ, R. (Org.) Pierre Bourdieu: Sociologia. São Paulo: Ática, 1983. (Coleção Grandes Cientistas Sociais, 39).

PATTI, A. R. A noção de sujeito discursivo. In: Fragmentum. Santa Maria: Laboratório Corpus, UFSM, n. 32, jan./mar. 2012. p. 13-17.

PÊCHEUX, M. Semântica e discurso: uma crítica à afirmação do óbvio. Tradução Eni Puccinelli Orlandi. Campinas: Unicamp, 1988.

PEDROSA, C. E. F. Análise crítica do discurso: uma proposta para a análise crítica da linguagem. Cadernos do CNLF, Rio de Janeiro, V. iii, n. 4, 2005. Disponível em: <www.filologia.org.br/ixcnlf/3/04.htm>. Acesso em: 10 dez. 2016.

PORTO-GONÇALVES, C. W. Apresentação da edição em português. In: LANDER, E. (Org). A colonialidade do saber: eurocentrismo e ciências sociais: perspectivas latinoamericanas. Buenos Aires: CLACSO, 2005. p. 3-5. (Colección Sur Sur).

ROVANE, C. The Bounds of Agency: an Essay in Revisionary Metaphysics. Princenton: Princenton University Press, 1998.

SANTOS, B. S.; MENESES, M. P. Epistemologias do sul. São Paulo: Cortez, 2010.

SANTOS, B. S. Um discurso sobre as ciências. São Paulo: Cortez, 2003.

SANTOS, R. P. Sujeito, discurso e ideologia: a constituição de identidades na cultura midiática. Culturas Midiáticas, Paraíba, v. II, n. 1, p. 1-9, jan./jun. 2009.

SEGAL, J. M. Agency and alienation: a theory of human presence. Savage, MD: Rowman \& Littlefield, 1991.

SOUZA, M. A. O ator social na sociologia contemporânea de Bourdieu e Touraine. Goiânia, [20--?]. Disponível em: <http://bit.ly/2nAEJON>. Acesso em: 20 dez. 2016.

TOURAINE, A. El sujeto: Un nuevo paradigma para comprender el mundo de hoy. Traducción María Tabuyo y Agustín Lopez Tobajas. Buenos Aires: Paidós, 2006.

TOURAINE, A. Igualdade e diversidade: o sujeito democrático. Tradução Modesto Florenzano. Bauru: Edusc, 1998.

TOURAINE, M. Critique de la modernité. Paris: Fayard, 1992.

VERONESE, M. V.; LACERDA, L. F. B. O sujeito e o indivíduo na perspectiva de Alain Touraine. Sociedade e Cultura, Goiânia, v. 14, n. 2, p. 419-426, jul./dez. 2011.

WODAK, R. De qué trata el análisis crítico del discurso (ACD). Resumen de su historia, sus conceptos fundamentales y sus desarrollos. In: WODAK, R.; MEYER, M. (Org.). Métodos de análisis crítico del discurso. Traducción Tomás Fernández Aúz y Beatriz Eguibar. Barcelona: Gedisa, 2003. p. 17-34.

Data de submissão: 09/01/2017. Data de aprovação: 15/03/2017. 